\title{
Pore-scale tomography and imaging: applications, techniques and recommended practice
}

\author{
Matthias Halisch $^{1}$, Holger Steeb ${ }^{2}$, Steven Henkel ${ }^{3}$, and Charlotte M. Krawczyk ${ }^{4,5}$ \\ ${ }^{1}$ Leibniz Institute for Applied Geophysics (LIAG), Stilleweg 2, 30655 Hanover, Germany \\ ${ }^{2}$ University of Stuttgart, Institute of Mechanics, Pfaffenwaldring 7, 70569 Stuttgart, Germany \\ ${ }^{3}$ Friedrich Schiller University Jena, Institute of Geosciences, Burgweg 11, 07749 Jena, Germany \\ ${ }^{4}$ GFZ German Research Center for Geosciences, Telegrafenberg, 14473 Potsdam, Germany \\ ${ }^{5}$ TU Berlin, Institute for Applied Geosciences, Ernst-Reuter-Platz 1, 10587 Berlin, Germany \\ Correspondence to: Matthias Halisch (matthias.halisch@liag-hannover.de)
}

Received: 1 July 2016 - Published: 20 July 2016

\section{Introduction to this special issue}

Three- and four-dimensional pore-scale imaging techniques have become an essential part in geosciences in the past years. The probably most commonly used techniques sum up to X-ray micro-computed tomography $(\mu-\mathrm{CT})$, synchrotroncomputed tomography (Sr-CT), neutron tomography (NT), positron emission tomography (PET) and focused ion beam scanning electron microscopy (FIB-SEM).

With these imaging techniques, structures and processes can be visualized, evaluated, compared, modeled and understood on the basis of first physical principles on a large variety of scales (from nanometer to centimeters and decimeters). Many of the investigated phenomena are of interdisciplinary interest or can add substantial new knowledge to many common assumptions and models. Besides, modern imaging methods enable the performance of numerical experiments on more or less in situ morphological information of the investigated specimen. This significantly increases the understanding of pore-scale processes as well as physics and pore-matrix interactions.

The number of peer-reviewed publications may act as an indicator for the importance of modern imaging techniques for geoscientific applications. Figure 1 gives an impression about the number of publications found by using a simple keyword search (here: method + geoscience) with the SCOPUS search engine, hosted by Elsevier (other platforms from other publishing services deliver very similar results).

According to this keyword search, FIB-SEM and $\mu$-CT feature by far the most publications. In addition, the aver- age increase over the last five years is roughly about $45 \%$ for both $\mu$-CT- and FIB-SEM-related publications. In contrast, the number of papers related to the other techniques remains remarkably constant during this period. These numbers also reflect the increased availability of bench-top X-ray $\mu$-CT and FIB-SEM systems within the geoscience community, due to new technical developments and reasonably cheap and hence affordable systems. Nevertheless, $\mu$-CT and FIB-SEM cannot cover the full range of scientific needs. Hence, we use this timely opportunity to showcase a broad range of all methods and of state-of-the-art applications within this issue.

The aim of this special issue is to highlight different techniques, methods and applications of pore-scale tomography and pore-scale imaging of natural rocks and soils, providing a comprehensive perspective on recent and future developments (technical, numerical and methodical) and applications.

\section{Content and highlights of this special issue}

Contributions from all fields of applied geosciences (e.g., geophysics, geology, rock mechanics, soil science, civil and environmental engineering, hydrology, volcanology, and many others), using different 3-D/4-D imaging techniques on different scales, are presented. This includes qualitative as well as quantitative case studies, new technical and scientific applications, recommended (best) practice and original research papers. Special emphasis has been given to contributions from interdisciplinary geo-scientific imaging for porescale-related research. In total, this special issue features 19 

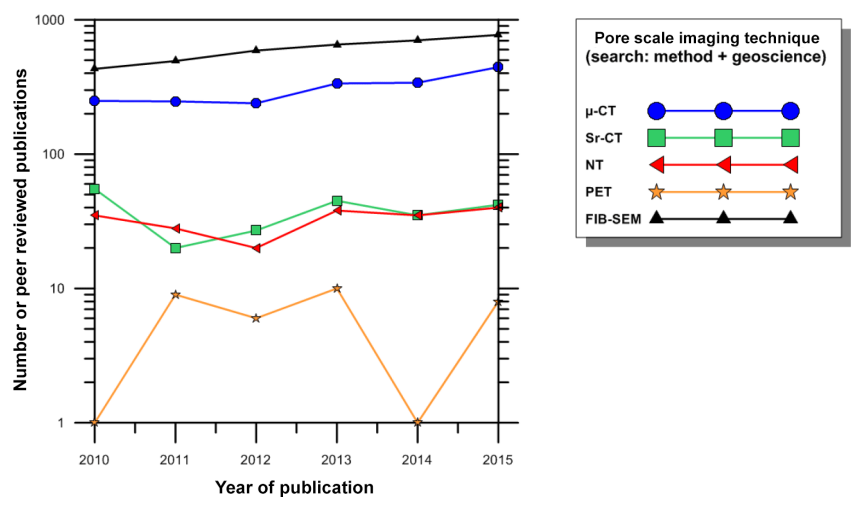

Figure 1. Results of the keyword search (method + geoscience) at SCOPUS for the last six years.
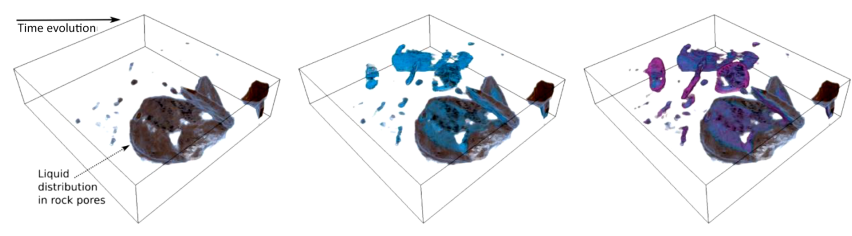

Figure 2. The fluid phase in the rock sample at three different times of the water ingress. Each volume is reconstructed from 60 projections using the CGLS-NLST method (Kaestner et al., 2015).

articles, covering a wide range of applications for modern pore-scale imaging methods.

Kaestner et al. (2015) provide a very comprehensive highlight paper about recent developments and applications in neutron imaging that enable investigation of the fluid distribution in porous samples. Here, the time-lapse series of the liquid ingress in the porous media allows the quantification of the liquid volumes (Fig. 2).

Schlüter et al. (2016) showcase the application of $\mu$-CT imaging for the analysis soil structure deformation, whereas Schmitt et al. (2016) present new research on the classification and quantification of pore shapes of reservoir rocks. Within the paper of Schoesser et al. (2016), research of the penetration behavior of bentonite suspensions into noncohesive media is presented. Saenger et al. (2016) present recommendations for digital carbonate rock physics performed on imaging data sets, and Kaufhold et al. (2016) investigated structures in Opalinus Clay on multiple scales after mechanical testing for the long-term storage of radioactive waste.

Kling et al. (2016) showcase a new approach of fluid flow modeling in fractured rocks, whereas Grathoff et al. (2016) modeled porosity and permeability of organic-rich Posidonia shales from FIB-SEM data sets. Kuhlenkampff et al. (2016a, b) provide an introduction to the method and application of Positron Emission Tomography.

The second highlight paper of this issue is from Dobson et al. (2016), who have pushed the limits of 4-D imaging of

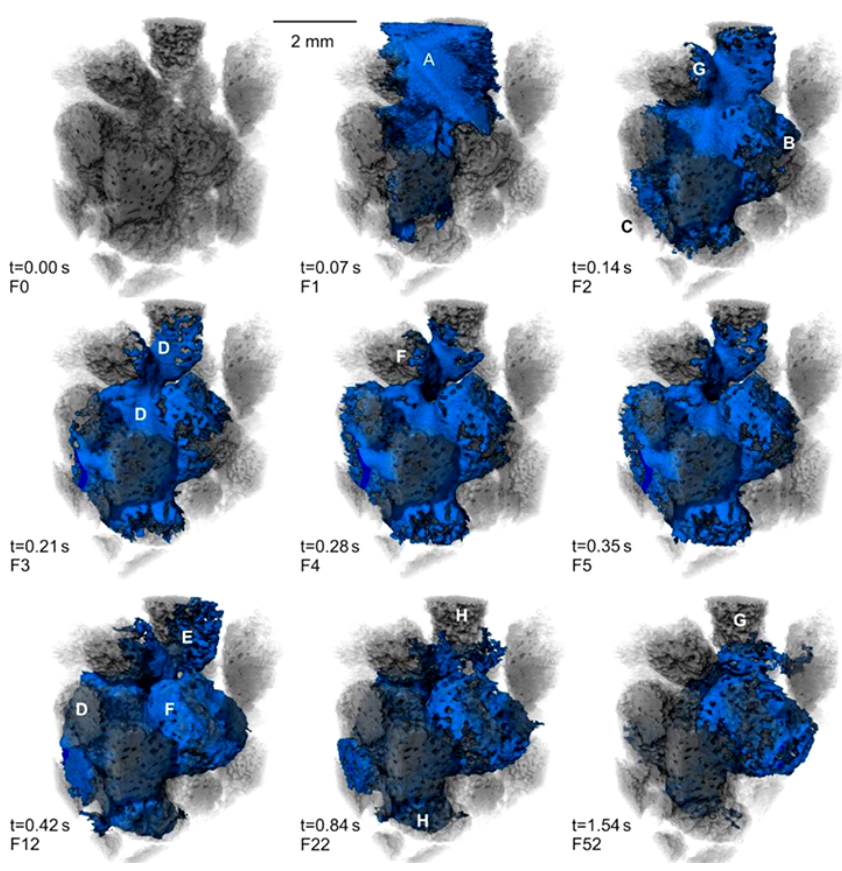

Figure 3. Time series showing the wetting of sandstone gravel under the first drip (3-D frame acquisition frequency $=0.07 / 3-\mathrm{D}$ volume, $14 \mathrm{~Hz}$ ). The first frame shows the dry sample with the sandstone grains rendered in semi-transparent grey. From the second frame the KI solution is shown in blue. The rendered volume is approximately $3.5 \mathrm{~mm} \times 3.5 \mathrm{~mm} \times 2 \mathrm{~mm}$. For further explanation and labeling of identified patches A-H, see Dobson et al. (2016).

sub-second dynamics by using synchrotron imaging to the edge. Aiming to describe wetting processes and the formation of rivulet networks, they evidence rapid changes in both the inter- and intra-grain fluid distribution (Fig. 3).

Followed by Luquot et al. (2016), who calculated structural and geometrical features from a limestone sample before and after a dissolution experiment, Sell et al. (2016) present a case study of processing Sr-CT data sets of gashydrate-bearing sediments.

Khan et al. (2016) and Chauhan et al. (2016) support the field of imaging data processing by presenting new research on single- and multi-phase segmentation and classification. Kahl et al. (2016) showcase with their paper new technical developments of a new X-ray transparent flow-through reaction cell for the surveillance of hydrothermal mineral-fluid interactions.

The paper by Peche et al. (2016) and Henkel et al. (2016) present a novel workflow for the determination of the interfacial surface area of a $\mathrm{CO}_{2}$-brine system as a case study on Heletz sandstone, and additionally a comparison of modeling results with an experimental $\mathrm{CO}_{2}$ study. Last but not least, Mukunoki et al. (2016) present research of CT investigations of structures in unconsolidated sand, relevant for environmental engineering. 
Acknowledgements. The editors would like to thank all authors and co-authors for sharing and publishing their newest research within this special issue. Accordingly, we would like to thank all reviewers for their time and knowledge to improve the quality of the contributions significantly. In addition, we would like to thank the team at Copernicus Publications for their great support and the uncomplicated and fruitful collaboration during the publication process.

\section{References}

Chauhan, S., Rühaak, W., Anbergen, H., Kabdenov, A., Freise, M., Wille, T., and Sass, I.: Phase Segmentation of X-Ray Computer Tomography Rock Images using Machine Learning Techniques: an Accuracy and Performance Study, Solid Earth Discuss., doi:10.5194/se-2016-44, in review, 2016.

Dobson, K. J., Coban, S. B., McDonald, S. A., Walsh, J. N., Atwood, R. C., and Withers, P. J.: 4-D imaging of sub-second dynamics in pore-scale processes using real-time synchrotron $\mathrm{X}$ ray tomography, Solid Earth, 7, 1059-1073, doi:10.5194/se-71059-2016, 2016.

Grathoff, G. H., Peltz, M., Enzmann, F., and Kaufhold, S.: Porosity and permeability determinations of organic rich Posidonia shales based on 3-D analyses by FIB-SEM microscopy, Solid Earth Discuss., doi:10.5194/se-2016-38, in review, 2016.

Henkel, S., Pudlo, D., Enzmann, F., Reitenbach, V., Albrecht, D., Ganzer, L., and Gaupp, R.: X-ray CT analyses, models and numerical simulations: a comparison with petrophysical analyses in an experimental $\mathrm{CO}_{2}$ study, Solid Earth, 7, 917-927, doi:10.5194/se-7-917-2016, 2016.

Luquot, L., Hebert, V., and Rodriguez, O.: Calculating structural and geometrical parameters by laboratory measurements and $\mathrm{X}$ ray microtomography: a comparative study applied to a limestone sample before and after a dissolution experiment, Solid Earth, 7, 441-456, doi:10.5194/se-7-441-2016, 2016.

Mukunoki, T., Miyata, Y., Mikami, K., and Shiota, E.: X-ray CT analysis of pore structure in sand, Solid Earth, 7, 929-942, doi:10.5194/se-7-929-2016, 2016.

Kaestner, A. P., Trtik, P., Zarebandkouki, M., Kazantsev, D., Snehota, M., Dobson, K. J., and Lehmann, E. H.: Recent developments in neutron imaging with applications for porous media research, Solid Earth Discuss., 7, 3481-3510, doi:10.5194/sed7-3481-2015, 2015.

Kahl, W.-A., Hansen, C., and Bach, W.: A new X-ray-transparent flow-through reaction cell for a $\mu$-CT-based concomitant surveillance of the reaction progress of hydrothermal mineral-fluid interactions, Solid Earth, 7, 651-658, doi:10.5194/se-7-651-2016, 2016.
Kaufhold, A., Zacher, G., Halisch, M., and Kaufhold, S.: X-ray Computed Tomography Investigation of Structures in Opalinus Clay from Large Scale to Small Scale after Mechanical Testing, Solid Earth Discuss., doi:10.5194/se-2016-43, in review, 2016.

Khan, F., Enzmann, F., and Kersten, M.: Multi-phase classification by a least-squares support vector machine approach in tomography images of geological samples, Solid Earth, 7, 481-492, doi:10.5194/se-7-481-2016, 2016.

Kling, T., Huo, D., Schwarz, J.-O., Enzmann, F., Benson, S., and Blum, P.: Simulating stress-dependent fluid flow in a fractured core sample using real-time X-ray CT data, Solid Earth Discuss., doi:10.5194/se-2016-41, in review, 2016.

Kulenkampff, J., Zakhnini, A., Gründig, M., and Lippmann-Pipke, J.: Quantitative experimental monitoring of molecular diffusion in clay with positron emission tomography, Solid Earth Discuss., doi:10.5194/se-2016-34, in review, 2016a.

Kulenkampff, J., Gründig, M., Zakhnini, A., and Lippmann-Pipke, J.: Geoscientific process monitoring with positron emission tomography (GeoPET), Solid Earth Discuss., doi:10.5194/se2016-35, in review, 2016b.

Peche, A., Halisch, M., Bogdan Tatomir, A., and Sauter, M.: Development of a numerical workflow based on $\mu$-CT imaging for the determination of capillary pressure-saturation-specific interfacial area relationship in 2-phase flow pore-scale porous-media systems: a case study on Heletz sandstone, Solid Earth, 7, 727739, doi:10.5194/se-7-727-2016, 2016.

Saenger, E. H., Vialle, S., Lebedev, M., Uribe, D., Osorno, M., Duda, M., and Steeb, H.: Digital Carbonate Rock Physics, Solid Earth Discuss., doi:10.5194/se-2016-45, in review, 2016.

Schlüter, S., Leuther, F., Vogler, S., and Vogel, H.-J.: X-ray microtomography analysis of soil structure deformation caused by centrifugation, Solid Earth, 7, 129-140, doi:10.5194/se-7-129-2016, 2016.

Schmitt, M., Halisch, M., Müller, C., and Fernandes, C. P.: Classification and quantification of pore shapes in sandstone reservoir rocks with 3-D X-ray micro-computed tomography, Solid Earth, 7, 285-300, doi:10.5194/se-7-285-2016, 2016.

Schoesser, B., Ghorbanpour, A., Halisch, M., and Thewes, M.: Visualization and Quantification of the Penetration Behavior of Bentonite Suspensions into the Pore Network of noncohesive Media by using $\mu$-CT Imaging, Solid Earth Discuss., doi:10.5194/se-2016-42, in review, 2016.

Sell, K., Saenger, E.-H., Falenty, A., Chaouachi, M., Haberthür, D., Enzmann, F., Kuhs, W. F., and Kersten, M.: On the path to the digital rock physics of gas hydrate bearing sediments - processing of in-situ synchrotron-tomography data, Solid Earth Discuss., doi:10.5194/se-2016-54, in review, 2016. 